\title{
Factors Associated with the Prevalence of Breast Cancer Risk: Perception of Northern Saudi Civic
}

\author{
Abdelbaset Mohamed Elasbali', Elyasa Mustafa Elfakia Mohammed1, Ziad Alonzi², \\ Haya Ali Atshan Al-Ruwaili' ${ }^{1}$, Amierah Hail Alsharari' ${ }^{1}$, Abdulrazaq Alshammari ${ }^{3}$, \\ Ali Saad Almansour ${ }^{3}$, Abdulwahab Abdulrahman Alsaman ${ }^{3}$, Hussain Gadelkarim Ahmed 3,4 \\ ${ }^{1}$ Department of Clinical Laboratory Sciences, College of Applied Medical Sciences, Jouf University, Qurayyat, Saudi Arabia \\ ${ }^{2}$ Department of Clinical Laboratory Sciences, College of Applied Medical Sciences, Jouf University, Sakaka, Saudi Arabia \\ ${ }^{3}$ Department of Pathology, College of Medicine, University of Hail, Hail, Saudi Arabia \\ ${ }^{4}$ Department of Histopathology and Cytology, University of Khartoum, Khartoum, Sudan \\ Email: hussaingad5@gmail.com
}

How to cite this paper: Elasbali, A.M., Mohammed, E.M.E., Alonzi, Z., Al-Ruwaili, H.A.A., Alsharari, A.H., Alshammari, A., Almansour, A.S., Alsaman, A.A. and Ahmed, H.G. (2019) Factors Associated with the Prevalence of Breast Cancer Risk: Perception of Northern Saudi Civic. Journal of Cancer Therapy, 10, 245-256.

https://doi.org/10.4236/jct.2019.103020

Received: February 21, 2019

Accepted: March 11, 2019

Published: March 14, 2019

Copyright $\odot 2019$ by author(s) and Scientific Research Publishing Inc. This work is licensed under the Creative Commons Attribution International License (CC BY 4.0).

http://creativecommons.org/licenses/by/4.0/ (c) (i) Open Access

\begin{abstract}
Background: The incidence of breast cancer is increasing in Saudi Arabia, chiefly in distant provinces with cases assigning advanced stages of the disease. This study aimed to evaluate the level of knowledge towards external exposure related to breast cancer risk factors in Qurayyat, Northern Saudi Arabia. Methodology: This descriptive study included 724 Saudi volunteers living in the city of Qurayyat, Northern Saudi Arabia. For females, only those agreeing to participate in the breast self-examination workshop were included and were further investigated for the presence of breast lumps. Results: In comparison of females vs. males, as for the point "Do you know food increases or decreases the risk of BC", 92 (15\%) women stated "Yes (Some prevented BC)" vs. 24 (24\%) of the men; 78 (12.5\%) women stated "Yes (Some caused BC)" vs. 25 (25\%) of the men. Referring to the socket "Overweight or obesity increases the risk of BC", 290 (46.5\%) women stated "Yes" vs. 53 (53\%) of the men. As for the inquiry "Viruses can increase the risk of BC", 370 (60\%) women stated "Yes" vs. 49 (49\%) of the men. Conclusion: There is a lack of breast cancer awareness in Northern Saudi Arabia with the existence of many women with undetected breast lumps. BSE is cost-effective, and it can be implemented in such inaccessible areas.
\end{abstract}

\section{Keywords}

Breast Cancer, Breast Self-Examination, Awareness, Saudi Arabia, Risk Factors 


\section{Introduction}

Females' breast cancer is one of the most frequent diseases and the leading cause of cancer-related mortality worldwide. In recent years, the prevalence of breast cancer is increasing in Saudi Arabia, particularly amongst younger women. This increase is attributed to the relative increase in the early detection and partially to the frequent exposure to several risk factors, which differ for different demographical factors [1]. In spite of the latest demands to step up the search for new breast cancer risk factors, targeting the existence information could prevent a lot of cases each year [2]. Tobacco, alcohol, type of dietary consumption, physical inactivity, overweight, occupation, infection, radiation (ionizing and solar) and use of hormones are major risk factors [3] [4].

Several epidemiological studies support the risk of radiation exposure to breast cancer etiology. However, the level of the risk is dose-dependent. Radiation exposure takes place before the age of 20 years, carrying the highest risk. Other features have an impact on the magnitude of dose-specific risk involving reached age, age at first full-term birth, parity, and possibly a history of benign breast disease, exposure to radiation while pregnant, and genetic factors [5]. Radiation-induced breast cancer risk from digital mammography screening is determined by dose changeability from screening and diagnostic, beginning age, and screening rate. Females with big breasts may be at greater radiation-induced risk [6].

Cigarette smoking is linked to an increased risk of breast cancer, particularly among those initiated smoking at adolescent or peri-menarcheal ages. Also, women with a family history of breast cancer gain a more significant risk with smoking [7] [8]. Obesity or overweight is a well-established risk for developing breast cancer, particularly in postmenopausal females with worse outcomes in all ages [9].

The increasing incidence of breast cancer in Saudi Arabia might be attributed to the low public knowledge and awareness toward breast cancer risk factors. Yet, there is a shortage of knowledge regarding the Saudi women level of consciousness. Therefore, the present study aimed to evaluate the level of understanding of external exposure related to breast cancer risk factors in Qurayyat, Northern Saudi Arabia.

\section{Materials and Methods}

This descriptive study included 724 Saudi volunteers living in the city of Qurayyat, Northern Saudi Arabia. Participants were targeted in different public settings in the city. Participants were and randomly selected by simple random method regardless of age, gender, education level or occupation. For females, only those agreeing to participate in the breast self-examination workshop were included were investigated for the presence of breast lumps. Males' participants were involved in serving as an internal control for the obtained information regarding breast cancer previous knowledge. A purposeful questionnaire was de- 
signed and used for securing of the necessary data. Besides the demographical data, the questionnaire included: "Do you know food increases or decreases the risk of $\mathrm{BC}$ ", "Overweight or obesity increases the risk of $\mathrm{BC}$ ", "The risk of $\mathrm{BC}$ may be associated with individual's weight", "Viruses can increase the risk of BC", "Cigarette smoking is a risk of BC", "Radiation exposure is a risk for BC", "Do you know food increases or decreases the risk of BC", "Overweight or obesity increases the risk of $\mathrm{BC}$ ", and "Use of cosmetics is a risk for $\mathrm{BC}$ ".

\subsection{Data Analysis}

Statistical Package for Social Sciences (version 16) was used for analysis and to perform a Pearson Chi-square test for statistical significance (p-value). The 95\% confidence level and confidence intervals were used. A p value less than 0.05 was considered statistically significant.

\subsection{Ethical Consent}

Each participant was asked to sign a written ethical consent during the questionnaire's interview. The informed ethical consent form was designed and approved by the ethical committee of the Applied Medical Science (Qurayyat, Jouf University, Saudi Arabia) Research Board.

\section{Results}

Out of 724 responded volunteers, 624 were females, and 100 were males (internal control). The mean age of the contributed women was $36 \pm$ STD 10.5 years with a range of 17 to 70 years old.

High frequency of participants was at the age group $<30$ years followed by 30 - 39 and 40 - 49 years constituting 239 (33\%), 186 (25.7\%) and 119 (16.4\%), respectively, as shown in Figure 1.

The vast majority of the study subjects were with university level of education $411(56.7 \%)$ trailed by secondary level 133 (18.4\%). Females were predominantly with university level 385 (62\%); hence, males were in excess at secondary level 32 (32\%), as shown in Figure 2.

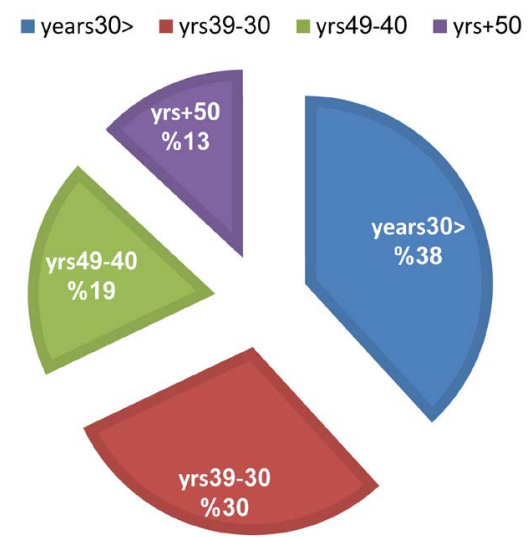

Figure 1. Females by age. 


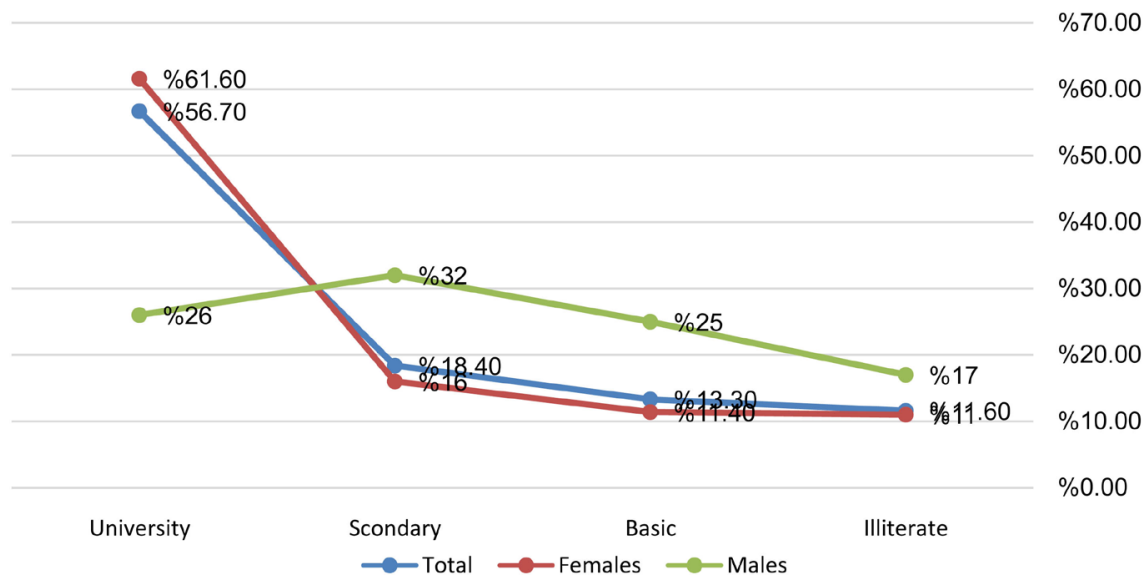

Figure 2. Study population by education.

Out of 624 recruited women, $473(75.8 \%)$ agreed to participate in breast self-examination (BSE), as well as, to do the training. The results of BSE showed 33 (7\%) breast lumps and 59 (12.5\%) likeness vicissitudes (see Figure 3).

In comparison of females vs. males, the point "Do you know food increases or decreases the risk of BC", 92(15\%) women stated "Yes (Some prevent BC)" vs. $24(24 \%)$ of the men; 78 (12.5\%) women stated "Yes (Some cause BC)" vs. 25(25\%) of the men, as indicated in Table 1 and Figure 4.

Referring to the socket "Overweight or obesity increases the risk of BC", 290 (46.5\%) women stated "Yes" vs. 53 (53\%) of the men. The point "The risk of BC may be associated with individual's weight", 264 (42.3\%) women specified vs. 16 (16\%) of the men, as indicated in Table 1 and Figure 4.

The inquiry "Viruses can increase the risk of BC," 370 (60\%) women stated "Yes" vs. 49 (49\%) of the men, as indicated in Table 1 and Figure 4.

Concerning the point "Cigarette smoking is a risk of BC," 444 (71.5\%) women stated "Yes" vs. 50 (50\%) of the men, as indicated in Table 1 and Figure 4.

The question "Radiation exposure is a risk for BC", 482 (77.8\%) women stated "Yes" vs. 41 (41\%) men, as indicated in Table 1 and Figure 4.

The Point "Use of cosmetics is a risk of BC", 354 (57.4\%) women replied "Yes" vs. only one man, as indicated in Table 1 and Figure 4.

As regard to the association between age and response to the $\mathrm{BC}$ risk factors, as it was summarized in Table 2. The inquiry "Do you know food increases or decreases the risk of $\mathrm{BC}$ ", point "Some foods can prevent $\mathrm{BC}$ ". The positive response was relatively stated similar among all age ranges with a slight increase in the age group 30 - 39 years.

The inquiry "Overweight or obesity increases the risk of BC", "Yes" responses were predominantly indicated by the age groups $<25$ years, $30-39$ and $40-49$ years (see Table 2 and Figure 5).

Indicating "Yes" virus infection can be a risk of BC, cigarette smoking, radiation exposure, and cosmetics usage were decreasingly notified by the age groups $<25$ years, $30-39$ and $40-49$ years (see Table 2 and Figure 5). 


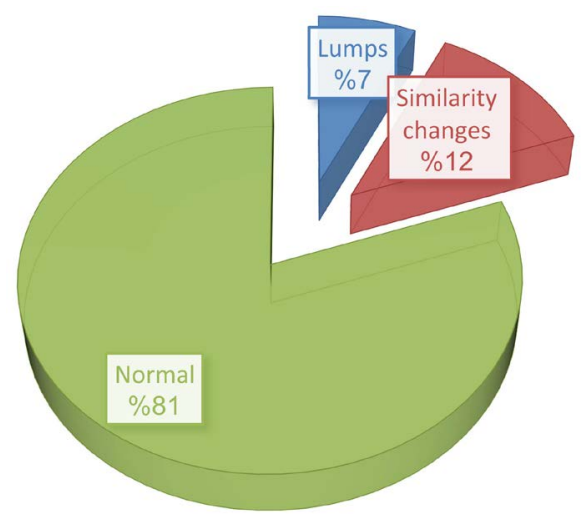

Figure 3. Results of BSE screening.

Table 1. Study subjects by gender and BC risk factors.

\begin{tabular}{|c|c|c|c|}
\hline Variable & Females & Males & Total \\
\hline \multicolumn{4}{|c|}{ Do you know food increases or decreases the risk of $B C$} \\
\hline Yes (Some prevent BC) & 92 & 24 & 116 \\
\hline Yes (Some cause BC) & 79 & 25 & 104 \\
\hline I don't know & 347 & 37 & 384 \\
\hline I know Both & 106 & 14 & 120 \\
\hline Total & 624 & 100 & 724 \\
\hline \multicolumn{4}{|c|}{ Overweight or obesity increases the risk of $B C$} \\
\hline Yes & 290 & 53 & 364 \\
\hline \multirow[t]{2}{*}{ No } & 326 & 44 & 349 \\
\hline & 616 & 97 & 713 \\
\hline \multicolumn{4}{|c|}{ The risk of BC may be associated with an individual s weight (wt) } \\
\hline With increased wt. & 264 & 16 & 280 \\
\hline With decrease wt. & 99 & 25 & 124 \\
\hline Both & 158 & 56 & 214 \\
\hline Total & 521 & 97 & 618 \\
\hline \multicolumn{4}{|c|}{ Viruses can increase the risk of $B C$} \\
\hline Yes & 370 & 49 & 419 \\
\hline No & 247 & 48 & 295 \\
\hline Total & 617 & 97 & 714 \\
\hline \multicolumn{4}{|c|}{ Cigarette smoking is a risk of $B C$} \\
\hline Yes & 444 & 50 & 494 \\
\hline No & 177 & 48 & 225 \\
\hline Total & 621 & 98 & 719 \\
\hline \multicolumn{4}{|c|}{ Radiation exposure is a risk for $B C$} \\
\hline Yes & 482 & 41 & 523 \\
\hline No & 138 & 55 & 193 \\
\hline Total & 620 & 96 & 716 \\
\hline \multicolumn{4}{|c|}{ Use of cosmetics is a risk for $B C$} \\
\hline Yes & 354 & 1 & 355 \\
\hline No & 263 & 1 & 264 \\
\hline Total & 617 & 2 & 619 \\
\hline
\end{tabular}




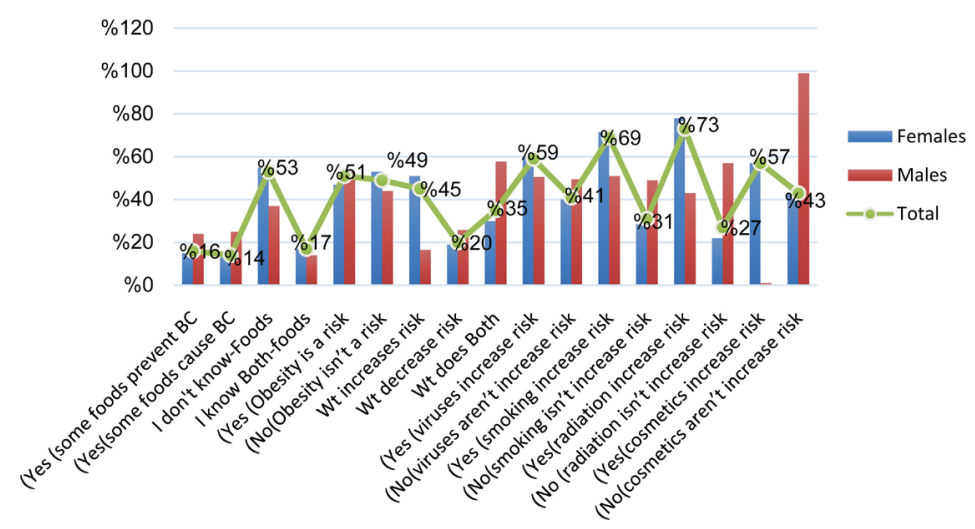

Figure 4. Gender by BC risk factors.

Table 2. Age by BC risk factors.

\begin{tabular}{|c|c|c|c|c|c|}
\hline Variable & $<30$ years & $30-39$ & $40-49$ & $50+$ & Total \\
\hline \multicolumn{6}{|c|}{ Do you know food increases or decreases the risk of $B C$} \\
\hline Yes (Some prevent BC) & 22 & 25 & 22 & 23 & 92 \\
\hline Yes (Some cause BC) & 25 & 25 & 16 & 13 & 79 \\
\hline I don't know & 141 & 102 & 67 & 39 & 349 \\
\hline I know Both & 51 & 33 & 14 & 7 & 105 \\
\hline Total & 239 & 185 & 119 & 82 & 625 \\
\hline \multicolumn{6}{|c|}{ Overweight or obesity increases the risk of $B C$} \\
\hline Yes & 97 & 95 & 62 & 36 & 290 \\
\hline No & 140 & 89 & 53 & 46 & 296 \\
\hline & 237 & 184 & 115 & 82 & 618 \\
\hline \multicolumn{6}{|c|}{ The risk of $B C$ may be associated with an individual s weight } \\
\hline With increased wt & 107 & 90 & 40 & 28 & 265 \\
\hline With decrease wt & 34 & 33 & 18 & 14 & 99 \\
\hline Both & 62 & 29 & 39 & 29 & 159 \\
\hline Total & 203 & 152 & 97 & 71 & 523 \\
\hline \multicolumn{6}{|c|}{ Viruses can increase the risk of $B C$} \\
\hline Yes & 160 & 98 & 67 & 45 & 370 \\
\hline No & 77 & 87 & 50 & 35 & 244 \\
\hline Total & 237 & 185 & 117 & 80 & 619 \\
\hline \multicolumn{6}{|c|}{ Cigarette smoking is a risk of $B C$} \\
\hline Yes & 167 & 136 & 89 & 53 & 445 \\
\hline No & 72 & 49 & 29 & 28 & 174 \\
\hline Total & 239 & 185 & 118 & 81 & 449 \\
\hline \multicolumn{6}{|c|}{ Radiation exposure is a risk for $B C$} \\
\hline Yes & 173 & 151 & 101 & 59 & 484 \\
\hline No & 64 & 34 & 17 & 23 & 138 \\
\hline Total & 237 & 185 & 118 & 82 & 62 \\
\hline \multicolumn{6}{|c|}{ Use of cosmetics is a risk for $B C$} \\
\hline Yes & 121 & 115 & 70 & 49 & 355 \\
\hline No & 117 & 69 & 46 & 32 & 264 \\
\hline Total & 238 & 184 & 116 & 81 & 619 \\
\hline
\end{tabular}


The distribution of the study population by the $\mathrm{BC}$ risk factors and education status was summarized in Table 3 and Figure 6. The question "Do you know food increases or decreases the risk of BC", was mostly positively stated by university participants, both for preventing $\mathrm{BC}$ and causes, representing 53/116 (45.7\%) and 54/104 (52\%), in this order. "Overweight or obesity increases the risk of BC", "Yes" answer as stated by 195/343 (57\%), 60/343 (17.5\%), and $46 / 343$ (13.4\%) of the university, secondary, and basic, correspondingly. "Viruses can increase the risk of $\mathrm{BC}$ ", "Cigarette smoking is a risk of BC", "Radiation exposure is a risk for BC", and "Use of cosmetics is a risk for BC" were increasingly responded "Yes" with the increase of the level of education, starting form illiterate, basic, secondary, and university, one-to-one (see Table 3 and Figure 6).

Table 3. Study subjects by the BC risk factors and education status.

\begin{tabular}{|c|c|c|c|c|c|}
\hline Variable & Illiterate & Basic & Secondary & University & Total \\
\hline \multicolumn{6}{|c|}{ Do you know food increases or decreases the risk of BC } \\
\hline Yes (Some prevent BC) & 20 & 21 & 22 & 53 & 116 \\
\hline Yes (Some cause BC) & 18 & 21 & 11 & 54 & 104 \\
\hline I don't know & 42 & 46 & 81 & 215 & 384 \\
\hline I know Both & 3 & 8 & 19 & 89 & 119 \\
\hline Total & 83 & 96 & 133 & 411 & 723 \\
\hline \multicolumn{6}{|c|}{ Overweight or obesity increases the risk of $B C$} \\
\hline Yes & 42 & 46 & 60 & 195 & 343 \\
\hline No & 40 & 48 & 70 & 210 & 370 \\
\hline Total & 82 & 94 & 130 & 407 & 713 \\
\hline \multicolumn{6}{|c|}{ The risk of $B C$ may be associated with individual weight } \\
\hline With increased wt. & 23 & 31 & 43 & 183 & 280 \\
\hline With decrease wt. & 10 & 27 & 31 & 56 & 124 \\
\hline Both & 46 & 29 & 30 & 109 & 214 \\
\hline Total & 79 & 87 & 104 & 348 & 618 \\
\hline \multicolumn{6}{|c|}{ Viruses can increase the risk of $B C$} \\
\hline Yes & 37 & 59 & 72 & 251 & 419 \\
\hline No & 46 & 35 & 59 & 155 & 295 \\
\hline Total & 83 & 94 & 131 & 406 & 714 \\
\hline \multicolumn{6}{|c|}{ Cigarette smoking is a risk of $B C$} \\
\hline Yes & 50 & 73 & 89 & 282 & 494 \\
\hline No & 33 & 22 & 44 & 126 & 225 \\
\hline Total & 83 & 95 & 133 & 408 & 719 \\
\hline \multicolumn{6}{|c|}{ Radiation exposure is a risk for $B C$} \\
\hline Yes & 53 & 65 & 82 & 323 & 523 \\
\hline No & 30 & 30 & 49 & 84 & 193 \\
\hline Total & 83 & 95 & 131 & 407 & 716 \\
\hline \multicolumn{6}{|c|}{ Use of cosmetics is a risk for $B C$} \\
\hline Yes & 39 & 44 & 65 & 207 & 355 \\
\hline No & 26 & 27 & 36 & 175 & 264 \\
\hline Total & 65 & 71 & 101 & 382 & 619 \\
\hline
\end{tabular}




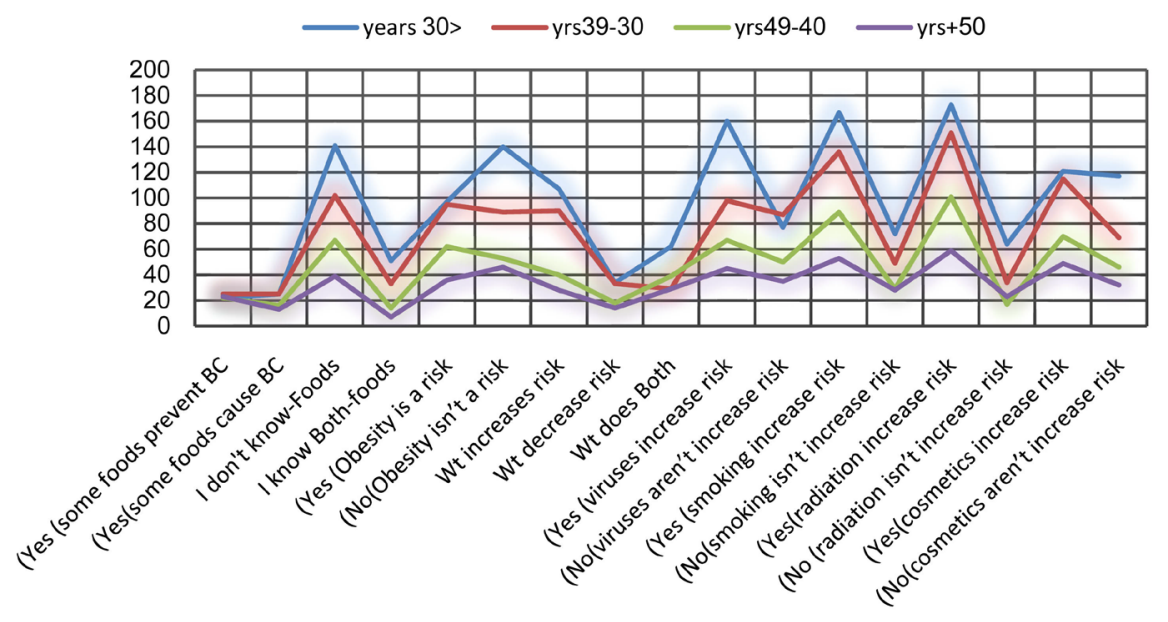

Figure 5. Age by BC risk factors.

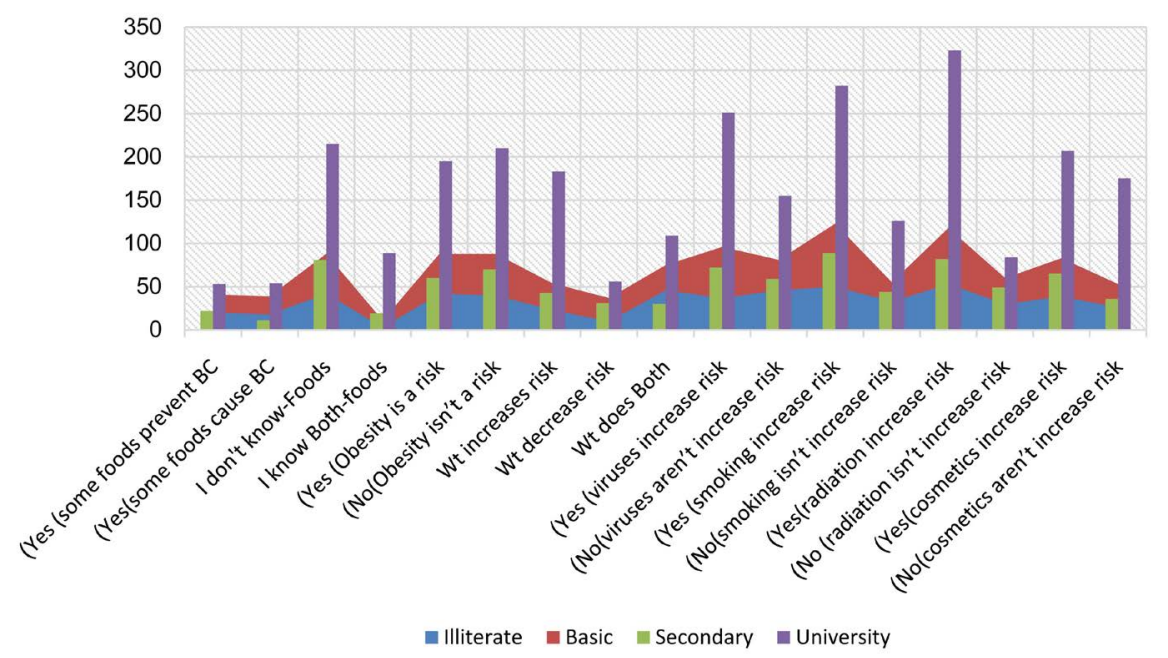

Figure 6. Education levels by BC risk factors.

\section{Discussion}

The incidence of breast cancer is increasing in Saudi Arabia, predominantly in inaccessible regions with cases imparting advanced stages of the disease, which might be attributed to the feebleness in the awareness and early detection efforts. Consequently, the present study aimed to strengthen the efforts of prevention and early detection through the implementation of BSE, as well as, to raise the level of awareness in Northern Saudi Arabia.

The existence of $7 \%$ of breast lumps in addition to $12.5 \%$ perceived breast changes in a randomized cross-sectional sample, predicts a severe liability of the disease in these remote areas. Women are recommended to practice BSE regularly and at least every month [10]. Women practice BSE is more likely to find their breast lesions at an earlier stage, which leads to early management and better prognosis. Although BSE is easy and cost-effective, some studies consider its effectiveness as an observational [11]. However, implementation of appropriate knowledge and practices on breast cancer and BSE at public setting levels are the 
critical steps for effective prevention measures across the general population.

The present study mainly focused on the assessment of the level of the awareness of the Saudi public towards the relationship between exposure to nominated common risk factors and breast cancer. The inquiry "Do you know food increases or decreases the risk of BC", 15\% women stated "Yes (Some food can prevent BC)" vs. $24 \%$ of the men. Moreover, $12.5 \%$ women stated "Yes (Some foods can cause BC)" vs. $25 \%$ of the men. These findings were displaying shallow levels of awareness. In a study examined the link between dietary factors, including food matters, and nutritional habits with breast cancer risk among women proposed that grilled meat and high-cholesterol food consumption and irregular intake habits are associated with a higher risk of breast cancer [12]. In a large pooled analysis, vegetable and fruit intake were inversely linked to the risk of breast cancer [13].

The inquiry "Overweight or obesity increases the risk of BC," $46.5 \%$ women indicated "Yes" vs. $53 \%$ of the men. These findings indicated a relatively average level of partakers' knowledge. Several studies reported that overweight and obesity elevate the risk of breast cancer, particularly in pre- and post-menopausal females [14] [15]. Clinical studies propose that obesity, besides promoting breast cancer aggressiveness, is associated with a decline in chemotherapy effectiveness, though the process intricate still indefinable [16].

The inquiry "Viruses can increase the risk of BC", 60\% women stated "Yes" vs. 49 (49\%) of the men. There is a rising form of evidence proposing that human papillomavirus (HPV) infection may play a vital role in the invasiveness of breast cancer. HPV infection may be involved in the development of some types of breast cancer [17]. The strong association between breast cancer and the Epstein Barr virus (EBV) was previously reported [18].

About the point "Cigarette smoking is a risk of BC", $71.5 \%$ women stated "Yes" vs. $50 \%$ of the men. While epidemiological suggestion on the role of active cigarette smoking in breast cancer risk has been inconsistent, the role of smoking in breast cancer etiology was established with a particular accentuate on timing and exposure [19]. A recent study has shown that smoking-related higher breast cancer risk was comparable for the five race/ethnicity groups in the Multiethnic Cohort (MEC) research and by estrogen (ER) and progesterone (PR) receptor status [20].

As for the question "Radiation exposure is a risk for BC", $77.8 \%$ women stated "Yes" vs. $41 \%$ men. Multiple diagnostic and therapeutic procedures involve the application of radiation. Ionizing radiation is known to promote tumorigenesis through inducing of mutations in the DNA of irradiated cells [21]. The risk of breast cancer has been linked to radiation exposure in the form of X-rays and mammography screening, but the risk depends on initiation age and exposure frequency. Females with large breasts may have a higher risk of radiation-induced breast cancer [22] [23].

The Point "Use of cosmetics is a risk of BC", 354 (57.4\%) women replied "Yes" vs. only one man. It was suggested that everyday use of certain cosmetics' 
ingredients was a strongly associated with the increased risk of breast cancer. Sufficient breast cancer carcinogenicity was linked to the use of cosmetic ingredients such as ethylene oxide and xenoestrogens. Some of these products have estrogen-like effects and others causing DNA damage of the human mammary epithelial cells [24]. Allowing these cosmetics on the skin for a time permits their absorption, and if they are applied on the breast, they may be absorbed directly and thus escape the systemic metabolism. Moreover, the combined interaction of cosmetics, environmental, and some pharmacological components may extensively elevate the risk of breast cancer for many women [25].

Concerning the age, an elevated level of awareness was noticed in the middle-age group, as well as, among people with a twice greater level of education. However, these factors require further assessment since age and education were not optimized in this trail.

Although the present study presented important data for health policy makers in Northern Saudi Arabia, for better preventive and early detection measures, it has some limitations including; it cross-sectional setting, including highly educated people, and a relatively younger population with lower risk.

\section{Conclusion}

There is a lack of breast cancer awareness in Northern Saudi Arabia with the existence of many women with undetected breast lumps. BSE is cost-effective and can be implemented in such inaccessible areas.

\section{Acknowledgements}

The authors would like to thank people of Qurayyat and the students at Faculty of applied Medical Science at Qurayyat.

\section{Conflicts of Interest}

The authors declare no conflicts of interest regarding the publication of this paper.

\section{References}

[1] Almutlaq, B.A., Almuazzi, R.F., Almuhayfir, A.A., Alfouzan, A.M., Alshammari, B.T., AlAnzi, H.S. and Ahmed, H.G. (2017) Breast Cancer in Saudi Arabia and Its Possible Risk Factors. Journal of Cancer Policy, 12, 83-89. https://doi.org/10.1016/j.jcpo.2017.03.004

[2] Colditz, G.A. and Bohlke, K. (2014) Priorities for the Primary Prevention of Breast Cancer. CA: A Cancer Journal for Clinicians, 64, 186-194. https://doi.org/10.3322/caac.21225

[3] Parkin, D.M., Boyd, L. and Walker, L.C. (2011) 16. The Fraction of Cancer Attributable to Lifestyle and Environmental Factors in the UK in 2010. British Journal of Cancer, 105, S77-S81.

[4] Colditz, G.A. and Bohlke, K. (2014) Priorities for the Primary Prevention of Breast Cancer. CA: A Cancer Journal for Clinicians, 64, 186-194. 
[5] Ronckers, C.M., Erdmann, C.A. and Land, C.E. (2004) Radiation and Breast Cancer: a Review of Current Evidence. Breast Cancer Research, 7, 21-32. https://doi.org/10.1186/bcr970

[6] Miglioretti, D.L., Lange, J., van den Broek, J.J., et al. (2016) Radiation-Induced Breast Cancer Incidence and Mortality from Digital Mammography Screening: A Modeling Study. Annals of Internal Medicine, 164, 205-214. https://doi.org/10.7326/M15-1241

[7] Jones, M.E., Schoemaker, M.J., Wright, L.B., Ashworth, A. and Swerdlow, A.J. (2017) Smoking and Risk of Breast Cancer in the Generations Study Cohort. Breast Cancer Research, 19, 118. https://doi.org/10.1186/s13058-017-0908-4

[8] Hampton, J.M., et al. (2016) Cigarette Smoking before and after Breast Cancer Diagnosis: Mortality from Breast Cancer and Smoking-Related Diseases. Journal of Clinical Oncology, 34, 1315-1322. https://doi.org/10.1200/JCO.2015.63.9328

[9] Picon-Ruiz, M., Morata-Tarifa, C., Valle-Goffin, J.J., Friedman, E.R. and Slingerland, J.M. (2017) Obesity and Adverse Breast Cancer Risk and Outcome: Mechanistic Insights and Strategies for Intervention. CA: A Cancer Journal for Clinicians, 67, 378-397. https://doi.org/10.3322/caac.21405

[10] Shapiro, S., Coleman, E.A., Broeders, M., Codd, M., de Konging, H., Fracheboud, J., Moss, S., Paci, E., Stachenko, S. and Ballard-Barbash, R. (1998) For the International Breast Cancer Screening Network (IBSN) and the European Network of Pilot Projects for Breast Cancer Screening Breast Cancer Screening Programmes in 22 Countries: Current Policies Administration and Guidelines. International Journal of Epidemiology, 27, 735-742. https://doi.org/10.1093/ije/27.5.735

[11] Hackshaw, A.K. and Paul, E.A. (2003) Breast Self-Examination and Death from Breast Cancer: A Meta-Analysis. British Journal of Cancer, 88, 1047-1053. https://doi.org/10.1038/sj.bjc.6600847

[12] Kim, J.H., Lee, J., Jung, S.Y. and Kim, J. (2017) Dietary Factors and Female Breast Cancer Risk: A Prospective Cohort Study. Nutrients, 9, 1331.

https://doi.org/10.3390/nu9121331

[13] Jung, S., Spiegelman, D., Baglietto, L., et al. (2013) Fruit and Vegetable Intake and Risk of Breast Cancer by Hormone Receptor Status. Journal of the National Cancer Institute, 105, 219-236. https://doi.org/10.1093/jnci/djs635

[14] Seiler, A., Chen, M.A., Brown, R.L. and Fagundes, C.P. (2018) Obesity, Dietary Factors, Nutrition, and Breast Cancer Risk. Current Breast Cancer Reports, 10, 14-27. https://doi.org/10.1007/s12609-018-0264-0

[15] Patel, A.V., Hildebrand, J.S. and Gapstur, S.M. (2014) Body Mass Index and All-Cause Mortality in a Large Prospective Cohort of White and Black U.S. Adults. PLoS ONE, 9, e109153. https://doi.org/10.1371/journal.pone.0109153

[16] Lehuédé, C., Li, X., Dauvillier, S., et al. (2019) Adipocytes Promote Breast Cancer Resistance to Chemotherapy, a Process Amplified by Obesity: Role of the Major Vault Protein (MVP). Breast Cancer Research, 21, 7. https://doi.org/10.1186/s13058-018-1088-6

[17] Khodabandehlou, N., Mostafaei, S., Etemadi, A., et al. (2019) Human Papilloma Virus and Breast Cancer: The Role of Inflammation and Viral Expressed Proteins. BMC Cancer, 19, 61. https://doi.org/10.1186/s12885-019-5286-0

[18] Yahia, Z.A., Adam, A.A., Elgizouli, M., et al. (2014) Epstein Barr Virus: A Prime Candidate of Breast Cancer Aetiology in Sudanese Patients. Infectious Agents and Cancer, 9, 9. https://doi.org/10.1186/1750-9378-9-9

[19] Catsburg, C., Miller, A.B. and Rohan, T.E. (2015) Active Cigarette Smoking and 
Risk of Breast Cancer. International Journal of Cancer, 136, 2204-2209. https://doi.org/10.1002/ijc.29266

[20] Gram, I.T., Park, S.Y., Maskarinec, G., Wilkens, L.R., Haiman, C.A. and Le Marchand, L. (2019) Smoking and Breast Cancer Risk by Race/Ethnicity and Oestrogen and Progesterone Receptor Status: The Multiethnic Cohort (MEC) Study. International Journal of Epidemiology, dyy290. https://doi.org/10.1093/ije/dyy290

[21] Repullés, J., Anglada, T., Soler, D., Ramírez, J.C., Genescà, A. and Terradas, M. (2019) Radiation-Induced Malignant Transformation of Pre-Neoplastic and Normal Breast Primary Epithelial Cells. Molecular Cancer Research, 18, 938. https://doi.org/10.1158/1541-7786.MCR-18-0938

[22] Marant-Micallef, C., Shield, K.D., Vignat, J., Cléro, E., Kesminiene, A., Hill, C., et al. (2018) The Risk of Cancer Attributable to Diagnostic Medical Radiation: Estimation for France in 2015. International Journal of Cancer, 66, S299.

https://doi.org/10.1002/ijc.32048

[23] Miglioretti, D.L., Lange, J., van den Broek, J.J., et al. (2016) Radiation-Induced Breast Cancer Incidence and Mortality from Digital Mammography Screening: A Modeling Study. Annals of Internal Medicine, 164, 205-214.

https://doi.org/10.7326/M15-1241

[24] Konduracka, E., Krzemieniecki, K. and Gajos, G. (2014) Relationship between Everyday Use Cosmetics and Female Breast Cancer. Polish Archives of Internal Medicine, 124, 264-269.

[25] Darbre, P.D. (2006) Environmental Oestrogens, Cosmetics and Breast Cancer. Best Practice \& Research Clinical Endocrinology \& Metabolism, 20, 121-143. https://doi.org/10.1016/j.beem.2005.09.007 